\title{
Preparation of S-containing heterocycles via novel reaction patterns of carbon disulfide with 1-lithiobutadienes and 1,4-dilithiobutadienes
}

\author{
Congyang Wang, ${ }^{a}$ Jinglong Chen, ${ }^{a}$ Qiuling Song, ${ }^{a}$ Zhiping $\mathrm{Li}^{a}$ and Zhenfeng $\mathrm{Xi}{ }^{a, b}{ }^{*}$ \\ ${ }^{a}$ Key Laboratory of Bioorganic Chemistry and Molecular Engineering of Ministry of Education, \\ College of Chemistry, Peking University, Beijing 100871, China, and ${ }^{b}$ State Key Laboratory of \\ Organometallic Chemistry, Shanghai Institute of Organic Chemistry, Chinese Academy of \\ Sciences, Shanghai 200032, China \\ E-mail: zfxi@pku.edu.cn
}

\section{Dedicated to Professor Zhitang Huang on the occasion of his 75th birthday}

(received 04 Dec 02; accepted 27 May 03; published on the web 30 May 03)

\begin{abstract}
Both carbophilic addition and thiophilic addition were involved in the first step intermolecular reaction of 1,4-dilithio-1,3-diene derivatives with carbon disulfide. Thus in situ generated carbophilic addition intermediates and thiophilic addition intermediates underwent a second step intramolecular carbophilic and thiophilic additions. Multiply substituted thiophenes were isolated as the results of cleavage of the $\mathrm{C}=\mathrm{S}$ double bonds, while thiopyran-2-thiones were produced via cycloaddition reactions. In addition to 1,4-dilithio-1,3-dienes, monolithio reagents also showed interesting reactions with carbon disulfide. Thiophenes were also generated in the reaction of 1-lithio-1,3-dienes with carbon disulfide.
\end{abstract}

Keywords: 1-Lithiobutadienes, 1,4-dilithiobutadienes, carbon disulfide, thiophenes, thiopyran2-thiones

\section{Introduction}

Addition reactions of thiocarbonyl compounds including cumulated thiocarbonyl groups such as $\mathrm{CS}_{2}$ with organolithium reagents are of fundamental interest because of two interesting points. Either carbophilic addition and thiophilic addition can be expected. ${ }^{1}$ As demonstrated in Scheme 1, the carbophilic addition (Scheme 1, type a) affords intermediates 1, lithiocarboxylates. In fact, among thiocarbonyl compounds, carbon disulfide has been accepted as the most useful substrate for the formation of carbon-carbon bonds. The thiophilic addition, which is shown as type $\mathbf{b}$ in Scheme 1, gives rise to the formation of intermediates 2 . Since both types of additions 
may take place, it is still difficult to predict which type of addition will proceed. Furthermore, the reaction mechanisms are still in debate.

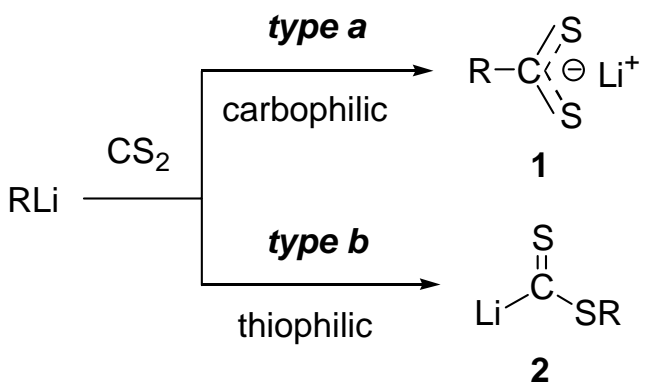

Scheme1. Reaction patterns of $\mathrm{CS}_{2}$ with organolithium compounds.

The second interesting point is selective application of the addition intermediates of $\mathrm{CS}_{2}$ with organolithium compounds. As given in Scheme 2, the generated addition products 1 or 2 can react in situ with electrophiles such as alkyl halides to afford products $\mathbf{3}$ or $\mathbf{4}$. Preparation of dithioesters 3 or $\mathbf{4}$ has been successfully achieved. ${ }^{2-4}$ In addition to the reaction with electrophiles, the addition products $\mathbf{1}$ or $\mathbf{2}$ may also react with nucleophiles such as RLi. However, surprisingly, application of this fundamental reaction with nucleophiles has not been investigated as such. ${ }^{5}$

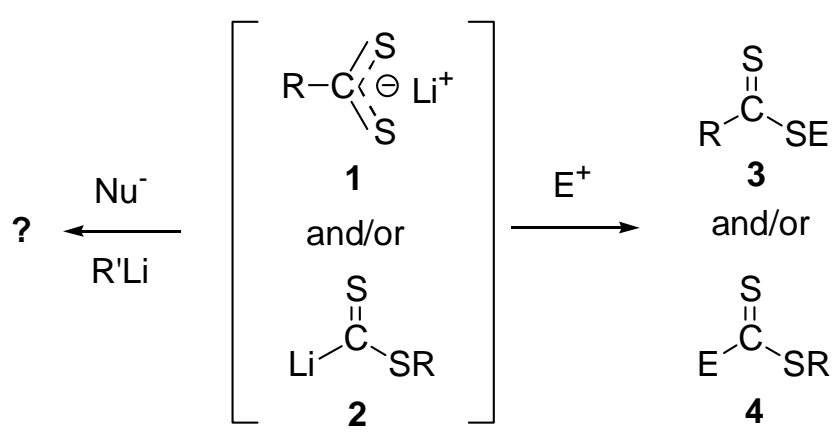

Scheme2. Application of the addition intermediates of $\mathrm{CS}_{2}$ with organolithium compounds.

Since we initially noticed the novel reaction patterns of 1,4-dilithio-1,3-diene derivatives 5 in $2000,{ }^{6}$ we have been investigating the reactions of 5 with various organic substrates. ${ }^{6-11}$ In order to study on the reaction of the addition intermediates $\mathbf{1}$ or $\mathbf{2}$ with nucleophiles, we used $\mathbf{5}$ as model compounds, expecting that selectivity can be improved and new types of reaction patterns can be discovered. ${ }^{5}$ As demonstrated in Scheme 3, both carbophilic addition intermediates 6 (Scheme 3, type a) and thiophilic addition intermediates 7 (Scheme 3, type b) can be expected as the first intermediate compounds. Intramolecular reactions of these intermediates may afford couples of products. Expected products are shown in Scheme 3. Similarly, both carbophilic addition and thiophilic addition can be expected in the subsequent intramolecular reactions of 6 and 7. For 6, carbophilic addition may afford cyclopentadienethiones $\mathbf{8}$ and dilithium derivative 
9. A six-membered S-containing dilithium compound $\mathbf{1 0}$ might be expected from the thiophilic addition in 6. For 7, thiophene derivative $\mathbf{1 1}$ and the six-membered S-containing dilithium compound $\mathbf{1 0}$ may be formed via carbophilic addition. If a second thiophilic addition takes place in $\mathbf{7}$, a seven-membered compound $\mathbf{1 2}$ can be expected.

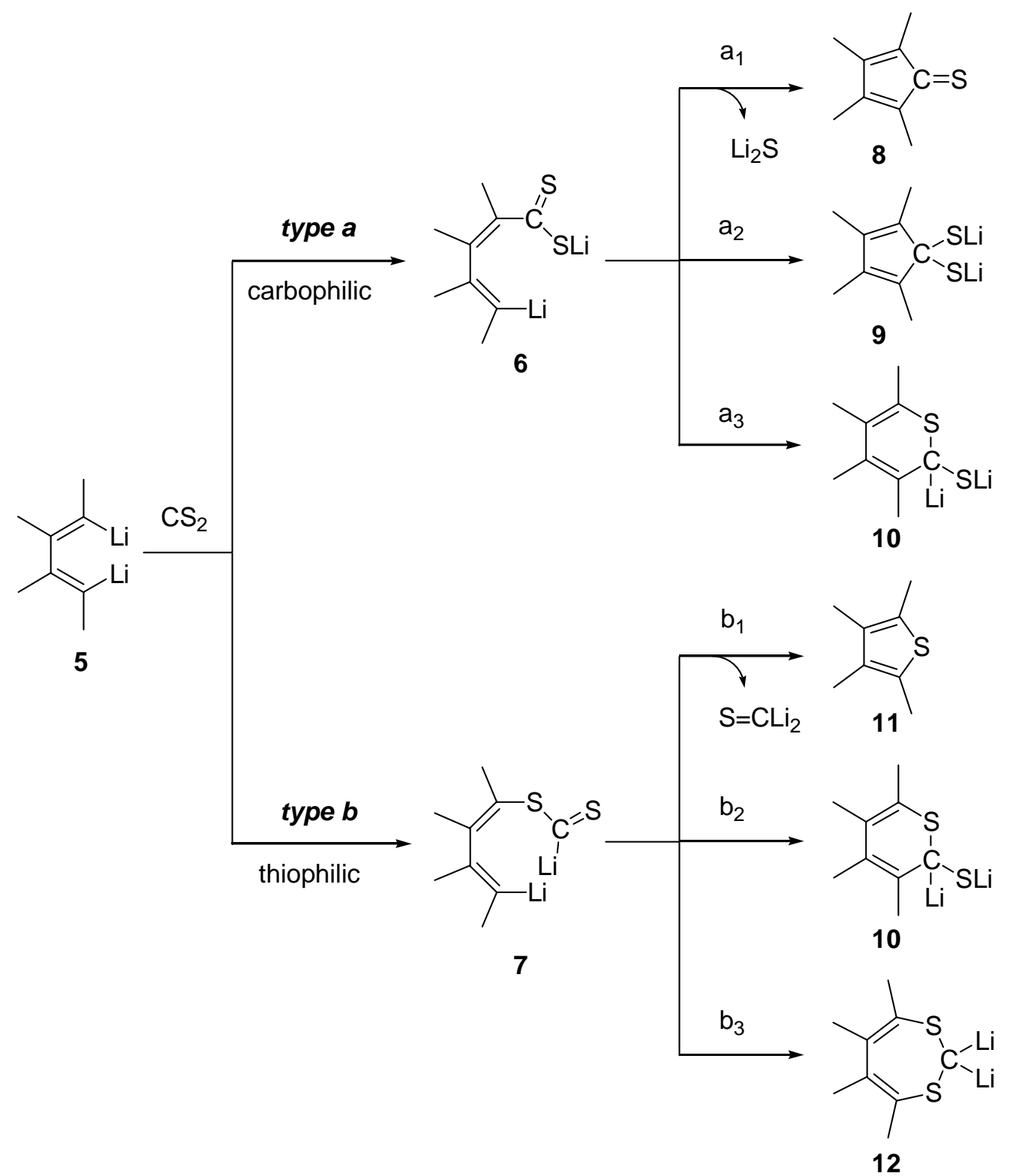

Scheme 3. Proposed reaction patterns of $\mathrm{CS}_{2}$ with 1,4-dilithio-1,3-diene derivatives.

Our recent studies have demonstrated that 1-lithiobutadiene derivatives 13 react with various organic substrates in a very much different manner from those of normal organolithium reagents. ${ }^{10,12}$ Thus, the reaction of 1-lithiobutadienes 13 with $\mathrm{CS}_{2}$ also interested us. As demonstrated in Scheme 4, the first addition intermediates may be carbophilic addition 
compound 14 and/or thiophilic addition compound 15. In this paper, we would like to report our results on the reaction of $\mathrm{CS}_{2}$ with 1,4-dilithiobutadienes and with 1-lithiobutadienes. ${ }^{5}$

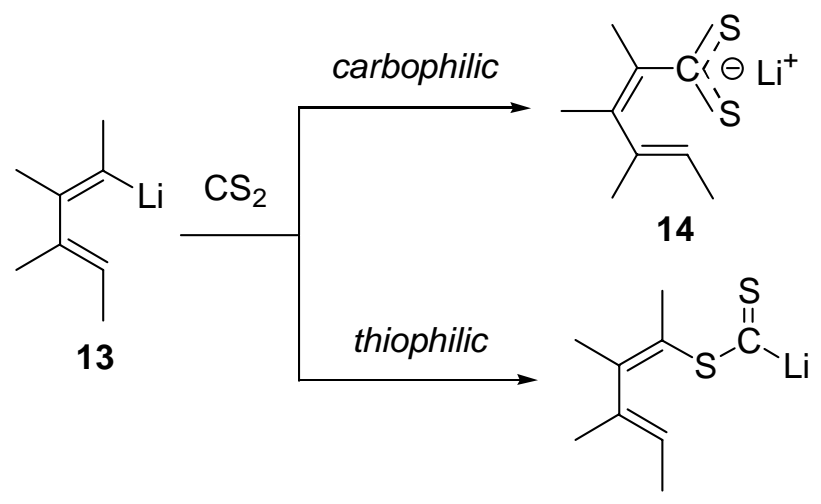

15

Scheme 4. Reaction patterns of CS2 with 1-lithiobutadiene derivatives.

\section{Results and Discussion}

Carbon dioxide reacted with 1,4-dilithio-1,3-diene derivatives 5 to afford cyclopentadienones in excellent yields, as we reported in $2000 .^{7}$ Since the reaction of organolithium reagents with thiocarbonyl groups may be analogous to those with carbonyl groups, the first expected product from the reaction of $\mathbf{5}$ with carbon disulfide was a thiocyclopentadienone $\mathbf{8}$. However, surpringly, no thiocyclopentadienone derivatives 8 were obtained for all the cases. Depending on the substituents of the dilithio reagents, either single products $\mathbf{1 1}$ or a mixture of $\mathbf{1 1}$ and $\mathbf{1 6}$ were obtained after hydrolysis of the reaction mixture (Scheme 5). ${ }^{13,14}$ No other products were obtained. The formation of thiopyran-2-thiones 16 were not expected. ${ }^{14}$

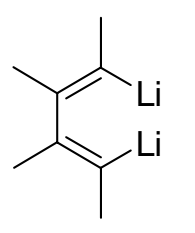

5

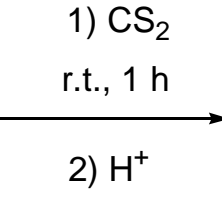

2) $\mathrm{H}^{+}$<smiles>Cc1sc(C)c(C)c1C</smiles>

11

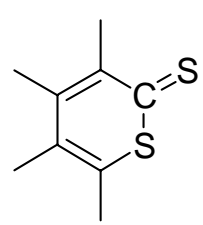

16

Scheme 5. Reaction of 1,4-dilithio-1,3-dienes with carbon disulfide.

Listed in Table 1 are results by the reaction of 1,4-dilithio-1,3-diene derivatives 5 with carbon disulfide. In cases of simply alkyl-substituted dilithio reagents 5a-d, the reactions afforded multiply substituted thiophenes $\mathbf{1 1}$ as the only prodcuts in most cases. Trace amount or non of thiopyran-2-thiones $\mathbf{1 6}$ were obtained. Interestingly, when a dilithio reagent 5e with $\mathrm{SiMe}_{3}$ as substituents was used, not only thiophene 11e but also thiopyran-2-thione 16e was obtained. These two compounds could be easily seperated. Thiophene 11e was obtained in $36 \%$ 
yield while thiopyran-2-thione $\mathbf{1 6 e}$ was obtained in $45 \%$ yield. The molar ratio of these two compounds was near 4:5. Later we found that formation of $\mathbf{1 1}$ and $\mathbf{1 6}$ was also related to the structure of the dilithio reagents. Similarly substituted with alkyl groups but with a cyclic structure, the dilithio reagent $\mathbf{5 f}$ aslo afforded $\mathbf{1 6 f}$ from its reaction with carbon disulfide.

Although the reason for the ratio of $\mathbf{1 1}$ and $\mathbf{1 6}$ is not clear yet, it is assumed that steric effect of the substituents and structural characteristics be essential for the selectivity of formation of $\mathbf{1 1}$ and/or 16. Thiopyran-2-thione derivatives $\mathbf{1 6}$ are favored when the substituents on the dilithio compounds are larger and when the structures are lacking flexibility.

Table 1. Reaction of $\mathrm{CS}_{2}$ with Dilithio Compounds ${ }^{a}$

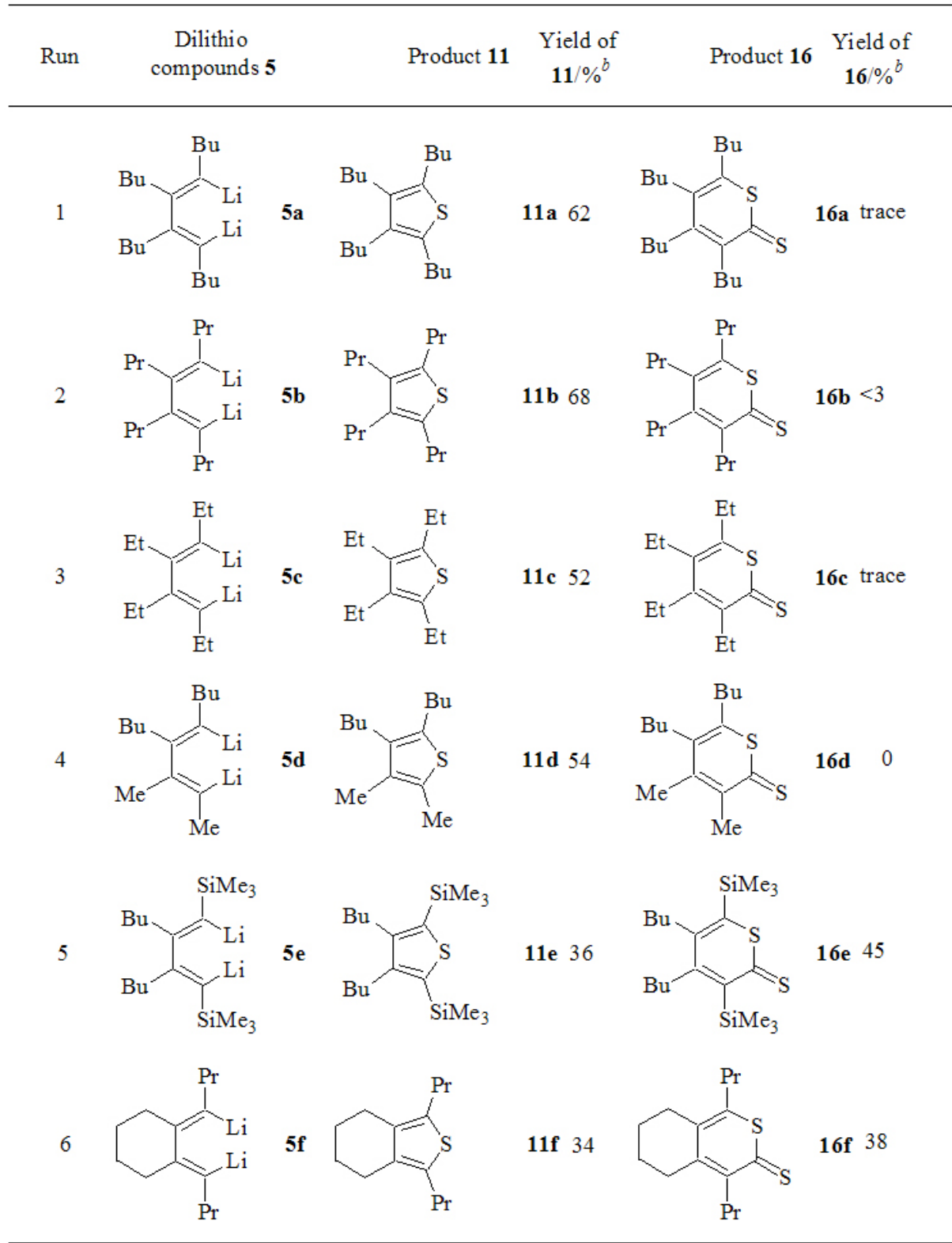

${ }^{a}$ Reaction conditions: Shown in Scheme 5. ${ }^{b}$ Isolated yields. 
As indicated in Scheme 3, lithiated intermediates 9, 10, 12 are assumed to be formed in the reactions of dilithio compounds 5 with carbon disulfide. In addition, $\mathrm{Li}_{2} \mathrm{~S}$ and $\mathrm{S}=\mathrm{CLi}_{2}$ are proposed to be generated in the reaction mixture. In order to understand the reaction mechanisms, we carried out several further reactions, trying to trap these lithiated intermediates. For examples, addition of aldehydes, ketones, $\mathrm{Me}_{3} \mathrm{SiCl}$, and so on to the reaction mixtures at various temperatures, however, did not give any meaningful results, except addition of MeI. Since reactions with MeI were pretty complicated, characterization of the structures of products was not easy. These results will be reported in due time.

At least three different reaction pathways have been proposed in the literature for the addition of organo-lithium and -magnesium compounds to thiocarbonyl groups. ${ }^{1,2}$ The formation of $\mathbf{1 1}$ may be rationalized in Scheme 3. For the formation of thiopyran-2-thione derivatives 16, both a concerted radical process ${ }^{14}$ and the following intermediate 17 (Scheme 6) might be proposed.

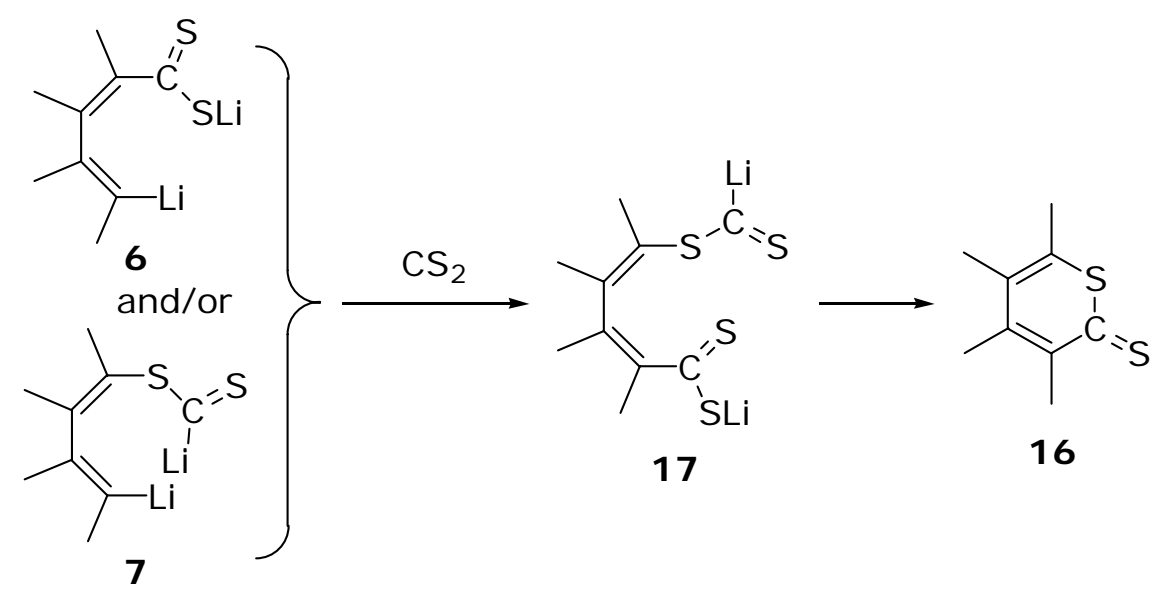

Scheme 6. One possible pathway for the formation of thiopyran-2-thione derivatives.

Although selectivity of reaction of 1-lithiobutadienes with $\mathrm{CS}_{2}$ was found to be worse than that of reaction of 1,4-dilithiobutadienes with $\mathrm{CS}_{2}$, the reaction pattern was novel. As demonstrated in Scheme 6, in addition to unknown products, thiophene compounds were also formed in these reactions. Some results are given in Figure 1. When the reaction mixture of $\mathrm{CS}_{2}$ with monolithio compounds at low temperature was treated with $\mathrm{MeI}, \mathrm{Me}_{3} \mathrm{SiCl}$, or $\mathrm{PhCOCl}$, yields of thiophene derivatives became much lower. No major expected methylated, silylated or acylated compounds were obtained.

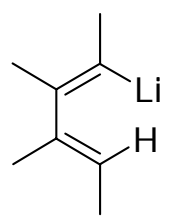

13
1) 1.2 equiv. $\mathrm{CS}_{2}$

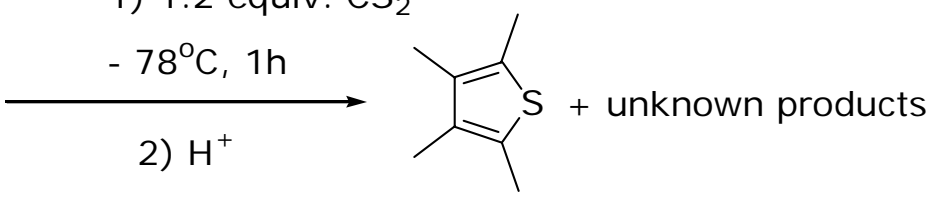

11

Scheme 7. Reaction of 1-lithiobutadienes with $\mathrm{CS}_{2}$. 
<smiles>CCCC=C(CCC)C(CCC)=C(C)C</smiles>

$13 a$<smiles>CCCc1sc(CCC)c(CCC)c1CCC</smiles>

11b: $33 \%$<smiles>CC(Cl)=C(C)C(=Cc1ccccc1)c1ccccc1</smiles>

13b<smiles>Cc1sc(-c2ccccc2)c(-c2ccccc2)c1C</smiles>

11g: $58 \%$<smiles>CSC=C(Cl)C(C)=C(C)C</smiles>

$13 c$

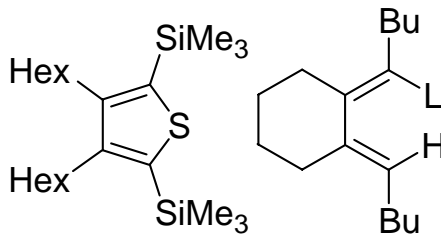

13d

11h: trace<smiles>CCCCc1c(Br)ccc(Br)c1Br</smiles>

11i: $48 \%$

\section{Figure 1}

\section{Experimental Section}

General Procedures. All reactions were conducted under a slightly positive pressure of dry, prepurified nitrogen using standard Schlenk line techniques when appropriate. Unless otherwise noted, all starting materials were commercially available and were used without further purification. Diethyl ether was refluxed and distilled from sodium benzophenone ketyl under a nitrogen atmosphere. $t$-BuLi was obtained from Kanto Chemicals Co. Ltd. Carbon disulfide was purified before use according to a reported procedure. ${ }^{15}$

${ }^{1} \mathrm{H}$ and ${ }^{13} \mathrm{C}$ NMR spectra were recorded at 300 and $75.4 \mathrm{MHz}$, respectively, in $\mathrm{CDCl}_{3}$ unless stated otherwise. 1,4-Dilithio-1,3-diene derivatives 5 were generated in situ from their corresponding 1,4-diiodo-1,3-dienes and $t$-BuLi. ${ }^{8}$ Monolithio 1,3-diene derivatives 13 were produced similarly from their corresponding monoiodo 1,3 -dienes. ${ }^{10}$

\section{A typical procedure for the preparation of thiophene and thiopyran-2-thione derivatives} from 1,4-dilithio-1,3-diene compounds

To a diethyl ether $(5 \mathrm{~mL})$ solution of 1,4-diiodo-1,3-butadiene $(1 \mathrm{mmol})$ at $-78{ }^{\circ} \mathrm{C}$ was added $t \mathrm{BuLi}\left(4.0 \mathrm{mmol}, 1.47 \mathrm{M}\right.$ in pentane). The above reaction mixture was then stirred at $-78{ }^{\circ} \mathrm{C}$ for $1 \mathrm{~h}$ to generate 1,4-dilithio-1,3-diene 5a, which was monitored by GC analysis or by TLC. After addition of carbon disulfide $(1.1 \mathrm{mmol})$ at $-78{ }^{\circ} \mathrm{C}$, the mixture was stirred at room temperature for $1 \mathrm{~h}$. The above reaction mixture was then quenched with $3 \mathrm{~N} \mathrm{HCl}$ and extracted with diethyl ether. The extract was washed with $\mathrm{NaHCO}_{3}$, brine and dried over $\mathrm{MgSO}_{4}$. The solvent was evaporated in vacuo to give a brown oil, which was purified by column chromatograph (silica gel, hexane) to afford 11a.

2,3,4,5-Tetrabutylthiophene (11a). Light yellow liquid, isolated yield 62\% (191 mg). ${ }^{1} \mathrm{H}$ NMR $\left(\mathrm{CDCl}_{3}, \mathrm{TMS}\right): \delta 0.90-0.98(\mathrm{~m}, 12 \mathrm{H}), 1.31-1.44(\mathrm{~m}, 16 \mathrm{H}), 2.41(\mathrm{t}, J=8.0 \mathrm{~Hz}, 4 \mathrm{H}), 2.66(\mathrm{t}, J=$ 
$8.0 \mathrm{~Hz}, 4 \mathrm{H}) ;{ }^{13} \mathrm{C} \mathrm{NMR}\left(\mathrm{CDCl}_{3}, \mathrm{TMS}\right): \delta 13.95,13.96,22.64,23.05,27.00,27.88,33.31,34.01$, 135.23, 136.81. HRMS calcd for $\mathrm{C}_{20} \mathrm{H}_{36} \mathrm{~S} 308.2538$, found 308.2546.

In cases of 5e and $\mathbf{5 f}$, the above reaction afforded a mixture of two compounds $11 \mathbf{e}$ and $\mathbf{1 6 e}$, 11f and 16f, respectively. Thiophene derivatives 11e and 11f were easily separated from thiopyran-2-thione derivatives $\mathbf{1 6 e}$ and $\mathbf{1 6 f}$ using column chromatograph (silica gel, hexane/ether $=4: 1)$.

2,3,4,5-Tetrapropylthiophene (11b). Light yellow liquid, isolated yield $68 \%(171 \mathrm{mg}) .{ }^{1} \mathrm{H}$ NMR ( $\mathrm{CDCl}_{3}$, TMS): $\delta$ 0.86-1.09 (m, 12H), 1.29-1.79 (m, 8H), 2.22-2.50 (m, 4H), 2.52-2.80 (m, $4 \mathrm{H}) ;{ }^{13} \mathrm{C} \mathrm{NMR}\left(\mathrm{CDCl}_{3}\right.$, TMS): $\delta$ 14.08, 14.45, 24.31, 25.10, 29.45, 30.29, 135.28, 136.81. HRMS calcd for $\mathrm{C}_{16} \mathrm{H}_{28} \mathrm{~S} 252.1912$, found 252.1924.

2,3,4,5-Tetraethylthiophene (11c). Light yellow liquid, isolated yield 52\% (102 mg). ${ }^{1} \mathrm{H}$ NMR $\left(\mathrm{CDCl}_{3}, \mathrm{TMS}\right): \delta 0.80(\mathrm{t}, J=7.5 \mathrm{~Hz}, 6 \mathrm{H}), 0.96(\mathrm{t}, J=7.5 \mathrm{~Hz}, 6 \mathrm{H}), 2.17(\mathrm{q}, J=7.5 \mathrm{~Hz}, 4 \mathrm{H}), 2.43$ (q, $J=7.5 \mathrm{~Hz}, 4 \mathrm{H}) ;{ }^{13} \mathrm{C} \mathrm{NMR}\left(\mathrm{CDCl}_{3}, \mathrm{TMS}\right): \delta 15.51,16.34,20.14,21.29,136.65,137.85$. HRMS calcd for $\mathrm{C}_{12} \mathrm{H}_{20} \mathrm{~S} 196.1286$, found 196.1278.

2,3-Dibutyl-4,5-dimethylthiophene (11d). Light yellow liquid, isolated yield 54\% (121 mg). ${ }^{1} \mathrm{H}$ NMR (CDCl 3 , TMS): $\delta$ 0.89-0.97 (m, 6H), 1.28-1.50 (m, 8H), $2.00(\mathrm{~s}, 3 \mathrm{H}), 2.28(\mathrm{~s}, 3 \mathrm{H}), 2.41$ $(\mathrm{t}, J=7.5 \mathrm{~Hz}, 2 \mathrm{H}), 2.65(\mathrm{t}, J=8.1 \mathrm{~Hz}, 2 \mathrm{H}) .{ }^{13} \mathrm{C} \mathrm{NMR}\left(\mathrm{CDCl}_{3}, \mathrm{TMS}\right): \delta 12.39,13.18,13.91$, $13.98,22.51,22.85,27.27,27.64,32.61,34.23,128.39,132.38,134.70,137.46$. HRMS calcd for $\mathrm{C}_{14} \mathrm{H}_{24} \mathrm{~S} 224.1599$, found 224.1610 .

2,5-Bis(trimethylsilyl)-3,4-dibutylthiophene (11e). Light yellow liquid, isolated yield 36\% (122 mg). ${ }^{1} \mathrm{H}$ NMR $\left(\mathrm{CDCl}_{3}\right): \delta 0.33(\mathrm{~s}, 18 \mathrm{H}), 0.96(\mathrm{t}, J=6.9 \mathrm{~Hz}, 6 \mathrm{H}), 1.40-1.53(\mathrm{~m}, 8 \mathrm{H}), 2.60(\mathrm{t}$, $J=6.9 \mathrm{~Hz}, 4 \mathrm{H}) ;{ }^{13} \mathrm{C} \mathrm{NMR}\left(\mathrm{CDCl}_{3}\right): \delta 0.55,13.92,23.36,29.54,34.56,138.56,151.27 . \mathrm{HRMS}$ calcd for $\mathrm{C}_{18} \mathrm{H}_{36} \mathrm{Si}_{2} \mathrm{~S} 340.2076$, found 340.2078.

Thiophene (11f). Light yellow liquid, isolated yield 34\% (75 mg). ${ }^{1} \mathrm{H} \mathrm{NMR}\left(\mathrm{CDCl}_{3}, \mathrm{TMS}\right): \delta$ $0.99(\mathrm{t}, J=7.5 \mathrm{~Hz}, 6 \mathrm{H}), 1.53-1.80(\mathrm{~m}, 8 \mathrm{H}), 2.39-2.75(\mathrm{~m}, 8 \mathrm{H}) .{ }^{13} \mathrm{C} \mathrm{NMR}\left(\mathrm{CDCl}_{3}, \mathrm{TMS}\right): \delta$ $13.98,23.46,24.41,25.07,29.75,133.39,133.80$. HRMS calcd for $\mathrm{C}_{14} \mathrm{H}_{22} \mathrm{~S} 222.1442$, found 222.1432.

Thione (16e). Deep brown liquid, isolated yield 45\% $(173 \mathrm{mg}),{ }^{1} \mathrm{H}$ NMR $\left(\mathrm{CDCl}_{3}\right): \delta 0.34(\mathrm{~s}$, 9H), 0.47 (s, 9H), 0.91-0.92 (m, 6H), 1.37-1.38 (m, 8H), 2.59 (t, $J=7.0 \mathrm{~Hz}, 2 \mathrm{H}), 2.68$ (t, $J=7.0$ $\mathrm{Hz}, 2 \mathrm{H}) ;{ }^{13} \mathrm{C} \mathrm{NMR}\left(\mathrm{CDCl}_{3}\right): \delta 0.10,4.00,13.72,13.84,22.98\left(2 \mathrm{CH}_{2}\right), 34.23,34.25,34.85$, $35.18,143.46,149.77,156.13,157.64,210.81$. HRMS calcd for $\mathrm{C}_{19} \mathrm{H}_{36} \mathrm{Si}_{2} \mathrm{~S}_{2} 384.1797$, found 384.1788 .

Thione (16f). Deep brown liquid, isolated yield 38\% (101 mg). ${ }^{1} \mathrm{H} \mathrm{NMR}\left(\mathrm{CDCl}_{3}, \mathrm{TMS}\right): \delta 0.64-$ $1.12(\mathrm{~m}, 6 \mathrm{H}), 1.25-2.00(\mathrm{~m}, 8 \mathrm{H}), 2.50-2.69(\mathrm{~m}, 8 \mathrm{H}) ;{ }^{13} \mathrm{C} \mathrm{NMR}\left(\mathrm{CDCl}_{3}, \mathrm{TMS}\right): \delta 13.87,14.52$, 20.13, 20.78, 21.36, 22.94, 26.41, 29.52, 32.32, 35.27, 133.16, 146.47, 148.08, 154.64, 199.87. HRMS calcd for $\mathrm{C}_{15} \mathrm{H}_{22} \mathrm{~S}_{2} 266.1163$, found 266.1158 .

A typical procedure for the preparation of thiophene derivatives from monolithio-1,3-diene compounds

To a diethyl ether $(5 \mathrm{~mL})$ solution of monoiodo-1,3-butadiene $(1 \mathrm{mmol})$ at $-78{ }^{\circ} \mathrm{C}$ was added $t \mathrm{BuLi}\left(2.0 \mathrm{mmol}, 1.47 \mathrm{M}\right.$ in pentane). The above reaction mixture was then stirred at $-78{ }^{\circ} \mathrm{C}$ for 
$1 \mathrm{~h}$ to generate monolithio-1,3-diene 13a, which was monitored by GC analysis or by TLC. After addition of carbon disulfide $(1.1 \mathrm{mmol})$ at $-78{ }^{\circ} \mathrm{C}$, the mixture was stirred at room temperature for $1 \mathrm{~h}$. The above reaction mixture was then quenched with $3 \mathrm{~N} \mathrm{HCl}$ and extracted with diethyl ether. The extract was washed with $\mathrm{NaHCO}_{3}$, brine and dried over $\mathrm{MgSO}_{4}$. The solvent was evaporated in vacuo to give a brown oil, which was purified by column chromatograph (silica gel, hexane) to afford 11b, which was exactly the same as that obtained by using dilithiobutadiene $\mathbf{5 b}$ as given above. In case of $\mathbf{1 3}$, no major products were obtained.

2,3-Dimethyl-4,5-diphenylthiophene (11g). ${ }^{16,17}$ White solid, isolated yield $58 \%$ (153 $\left.\mathrm{mg}\right)$. mp:108-109 ${ }^{\circ} \mathrm{C}$ (lit. ${ }^{16}: 103{ }^{\circ} \mathrm{C}$ ); ${ }^{1} \mathrm{H}$ NMR (CDCl 3 , TMS): $\delta 1.97$ (s, 3H), 2.41 (s, 3H), 7.07-7.35 $(\mathrm{m}, 10 \mathrm{H}),{ }^{13} \mathrm{C} \mathrm{NMR}\left(\mathrm{CDCl}_{3}, \mathrm{TMS}\right): \delta 13.37,13.47,126.52,126.80,128.12,128.29,128.82$, 130.24, 131.84, 133.83, 134.70, 135.37, 137.61, 139.34. HRMS calcd for $\mathrm{C}_{18} \mathrm{H}_{16} \mathrm{~S} 264.0973$, found 264.0971. Anal. Calcd. for $\mathrm{C}_{18} \mathrm{H}_{16} \mathrm{~S}: \mathrm{C}, 81.82 ; \mathrm{H}, 6.06$. Found: C, 81.58; H, 6.33.

Thiophene (11i). Light yellow liquid, isolated yield 48\% (120 mg). ${ }^{1} \mathrm{H} \mathrm{NMR}\left(\mathrm{CDCl}_{3}, \mathrm{TMS}\right)$ : 80.88-0.95 (m, 6H), 1.26-1.73 (m, 12H), 2.53-2.65 (m, 8H), $\left.{ }^{13} \mathrm{C} \mathrm{NMR} \mathrm{(} \mathrm{CDCl}_{3}, \mathrm{TMS}\right): \delta 13.90$, 22.50, 23.46, 25.07, 27.36, 33.34, 133.31, 133.94. HRMS calcd for $\mathrm{C}_{16} \mathrm{H}_{26} \mathrm{~S} 250.1755$, found 250.1754 .

\section{Acknowledgements}

This work was partially supported by the Natural Science Foundation of China (29825105, 20172003, 20232010) and the Major State Basic Research Development Program (G2000077502-D). Cheung Kong Scholars Programme, Qiu Shi Science \& Technologies Foundation, and Dow Corning Corporation are gratefully acknowledged.

\section{References and Notes}

1. (a) Wakefield, B. J. Organolithium Methods, Academic Press, London, 1988, p 67. (b) Wakefield, B. J. in Comprehensive Organometallic Chemistry, ed. G. Wilkinson, Pergamon, Oxford, 1982, chapter 44.

2. (a) Seyferth, D.; Hui, R. C. Tetrahedron Lett. 1984, 25, 2623. (b) Meijer, J.; Ruitenberg, K.; Westmijze, H.; Vermeer, P. Synthesis 1981, 551.

3. Maercker, A.; van de Flierdt, J.; Girreser, U. Tetrahedron 2000, 56, 3373.

4. (a) Micetich, R. G. Can. J. Chem. 1970, 48, 2006. (b) P. Beak, P.; Worley, J. W. J. Am. Chem. Soc. 1972, 94, 597. (c) Hartzler, H. D. J. Am. Chem. Soc. 1973, 95, 4379. (d) Schaumann, E.; Walter, W. Chem. Ber. 1974, 107, 3562. (e) Commercon, A.; Ponsinet, G. Tetrahedron Lett. 1985, 26, 5131. (f) Alberti, A.; Benaglia, M.; Macciantelli, D.; Marcaccio, M.; Olmeda, A.; Pedulli, G. F.; Roffia, S. J. Org. Chem. 1997, 62, 6309. 
5. Preliminary results on the reaction of $\mathrm{CS}_{2}$ with 1,4-dilithio-1,3-dienes have been reported. Chen, J.; Song, Q.; Xi, Z. Tetrahedron Lett. 2002, 43, 3533.

6. Xi, Z.; Song, Q. J. Org. Chem. 2000, 65, 9157.

7. Xi, Z.; Li, P. Angew. Chem., Int. Ed. Engl. 2000, 39, 2950.

8. Xi, Z.; Song, Q.; Chen, J.; Guan, H.; Li, P. Angew. Chem., Int. Ed. Engl. 2001, 40, 1913.

9. Song, Q.; Chen, J.; Jin, X.; Xi, Z. J. Am. Chem. Soc. 2001, 123, 10419.

10. Chen, J.; Song, Q.; Wang, C.; Xi, Z. J. Am. Chem. Soc. 2002, 124, 6238.

11. Chen, J.; Song, Q.; Li, P.; Guan, H.; Jin, X.; Xi, Z. Org. Lett. 2002, 4, 2269.

12. Song, Q.; Li, Z.; Chen, J.; Wang, C.; Xi, Z. Org. Lett. 2002, 4, 4627.

13. (a) Fagan, P. J.; Buchwald, S. L.; Fang, Q. J. Org. Chem. 1989, 54, 2793. (b) Fagan, P. J.; Nugent, W. A.; Calabrese, J. C. J. Am. Chem. Soc. 1994, 116, 1880.

14. Yamamoto, Y.; Takagishi, H.; Itoh, K. J. Am. Chem. Soc. 2002, 124, 28.

15. Purification of Laboratory Chemicals, Armarego, W. L. F.; Perrin, D. D. Eds., ButterworthHeinemann, Bath, $4^{\text {th }}$ edition, 1998, p 136.

16. Schrauzer, G. N.; Mayweg, V. P. J. Am. Chem. Soc. 1965, 87, 1483.

17. (a) Nakayama, J.; Machida, H.; Hoshino, M. Tetrahedron Lett. 1985, 26, 1981. (b) Nakayama, J.; Machida, H.; Saito, R.; Hoshino, M. Tetrahedron Lett. 1985, 26, 1983. 